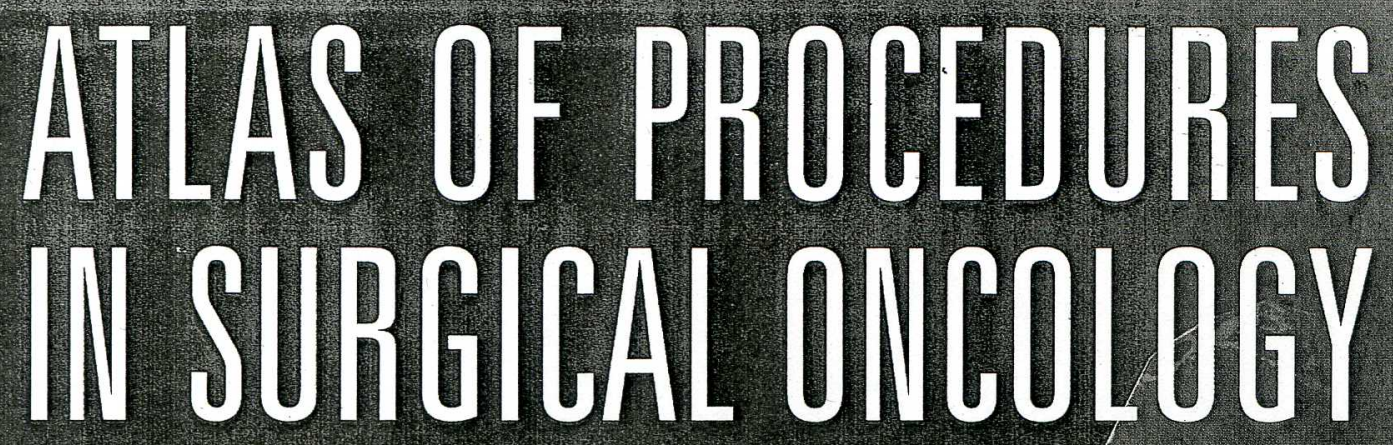
WTIH CAITICAL, EVIDEECEE BASED COUMENUTARY NOTES

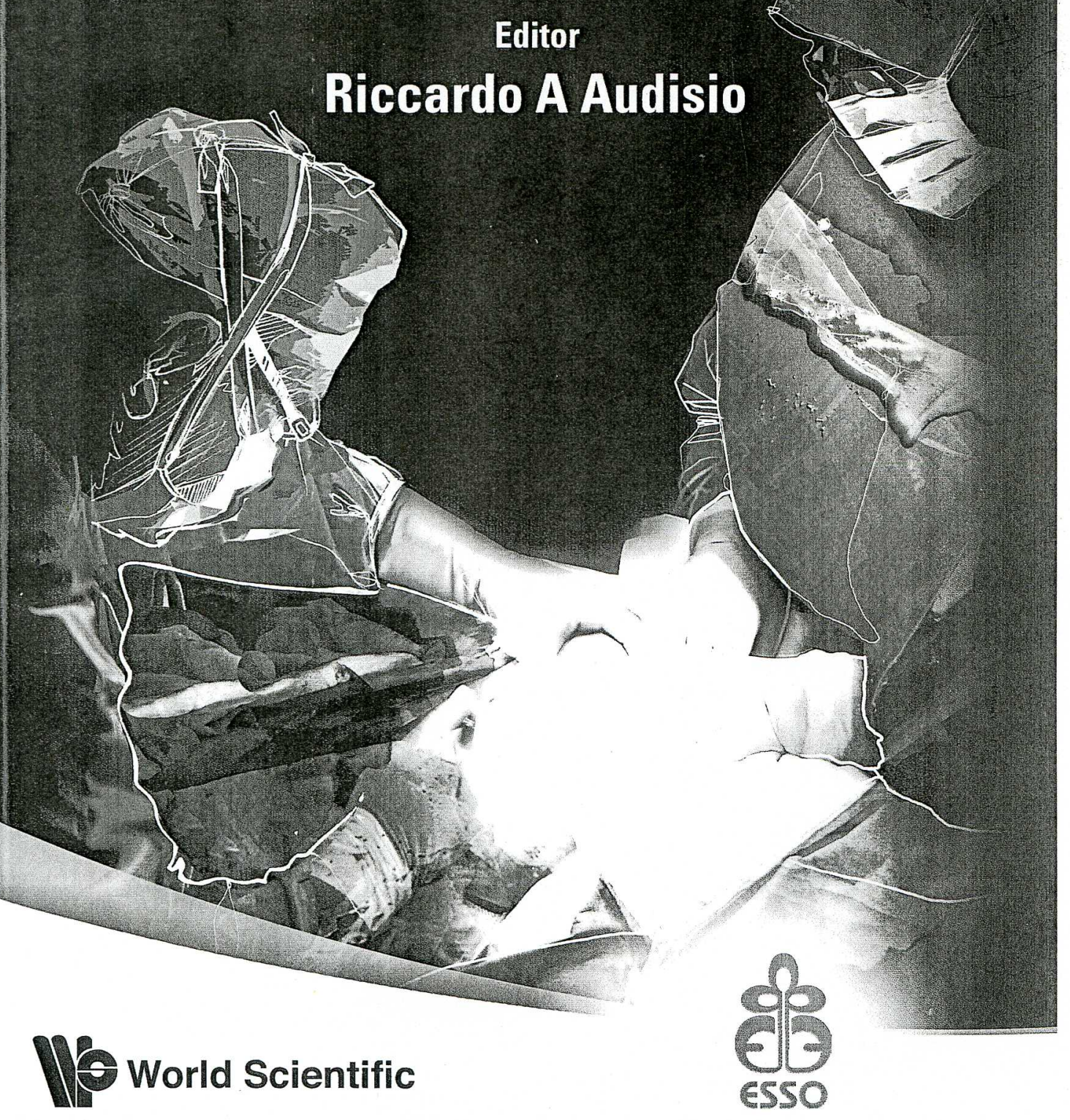




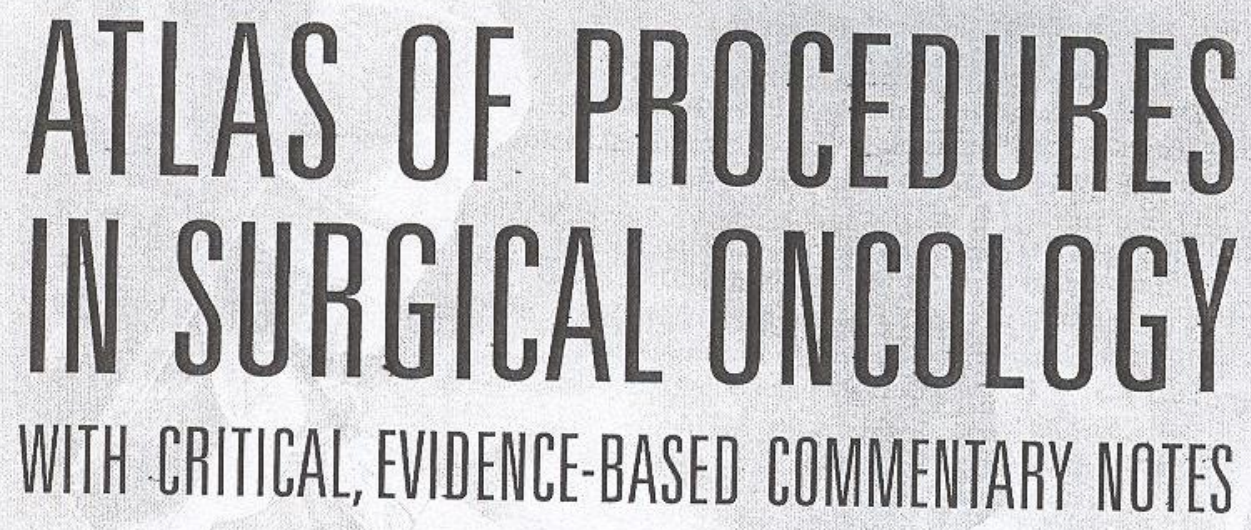

\section{Editor}

\section{Riccardo A Audisio}

Whiston Hospital, University of Liverpool, UK

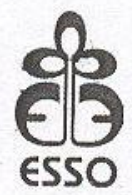

Ne World Scientific 


\section{Published by}

World Scientific Publishing Co. Pte. Ltd.

5 Toh Tuck Link, Singapore 596224

USA office: 27 Warren Street, Suite 401-402, Hackensack, NJ 07601

UK office: 57 Shelton Street, Covent Garden, London WC2H 9HE

\section{Library of Congress Cataloging-in-Publication Data}

Atlas of procedures in surgical oncology with critical, evidence-based commentary notes (with DVD-ROM) / editor, Riccardo A. Audisio.

$$
\text { p. ; cm. }
$$

Includes bibliographical references and index.

ISBN-13: 978-981-283-293-1 (hardcover : alk. paper)

ISBN-10: 981-283-293-9 (hardcover : alk. paper)

1. Cancer--Surgery--Atlases. I. Audisio, Riccardo A.

[DNLM: 1. Neoplasms--surgery--Atlases. QZ 17 A88046 2009]

RD651.A765 2009

616.99'4059--dc22

\section{British Library Cataloguing-in-Publication Data}

A catalogue record for this book is available from the British Library.

Copyright $(2010$ by World Scientific Publishing Co. Pte. Ltd.

All rights reserved. This book, or parts thereof, may not be reproduced in any form or by any means, electronic or mechanical, including photocopying, recording or any information storage and retrieval system now known or to be invented, without written permission from the Publisher.

For photocopying of material in this volume, please pay a copying fee through the Copyright Clearance Center, Inc., 222 Rosewood Drive, Danvers, MA 01923, USA. In this case permission to photocopy is not required from the publisher.

Typeset by Stallion Press

Email: enquiries@stallionpress.com

Printed by FuIsland Offset Printing (S) Pte Ltd, Singapore 


\title{
Minimally Invasive Techniques for Early Lung Cancer
}

\author{
Contardo Vergani ${ }^{*},{ }^{\dagger}$, Luca Despini ${ }^{\dagger}$ and Giancarlo Roviaro ${ }^{\dagger}$
}

\section{BASIC CONSIDERATIONS}

Although a number of authors ${ }^{1-5}$ advocate VATS for staging and treating stage I lung cancer, this approach is still widely debated. More than 16 years since the first videothoracoscopic lobectomy in $1991{ }^{6}$ thoracoscopic major resections still have to achieve diffusion, mainly owing to persistent concerns about their oncologic validity.

Initial fear of intraoperative accidents has gradually faded and, at present, evidence shows that VATS lobectomies are safe, with mortality and morbidity comparable to conventional procedures. In our series of 230 VATS lobectomies for cancer, we recorded no intraoperative mortality, and a postoperative mortality rate of $0.87 \% .{ }^{1}$ Similar results have been observed in other series. ${ }^{5,7,9}$ Altough videothoracoscopic dissection of the pulmonary vessels is a delicate procedure, the risk of intraoperative bleeding has proved small. ${ }^{1-5,7-9}$

\footnotetext{
*Corresponding author.

Department of Surgical Sciences, State University of Milan and Department of General Surgery, Ospedale Maggiore Policlinico, Mangiagalli e Regina Elena, IRCCS, Milan, Via Francesco Sforza 35, 20122 Milano, Italy. E-mail: contardo.vergani@
unimi.it
} 
According to several randomised studies, postoperative pain is reduced in comparison with muscle-sparing thoracotomy, ${ }^{1,5,8-10}$ even though others could not find any difference. ${ }^{11}$

According to some non-randomised studies, pulmonary function seems better after VATS than after conventional lobectomy. ${ }^{9}$

Technical differences regard the site and size of the utility thoracotomy, the use of the rib spreader, and the site of insertion of the trocars. Most authors agree that thoracoscopic lobectomy should entail separate dissection and securing of the hilar elements. Simultaneous stapling mass ligation of the hilum ${ }^{12}$ is considered an unorthodox procedure by most.

The oncologic validity of VATS lobectomies for cancer is still unproven, but evidence is mounting that they offer results similar to those of open lobectomy.

Concern about increased recurrence rates or tumour seeding on the port sites seems inconsistent, provided that careful manipulation during dissection and wound protection during the extraction of the specimen is adopted. We have not experienced any recurrence, and in the other clinical series the recurrence rate has been low or null. $1,7,8$

Regarding long term results, in our experience VATS lobectomy for stage I lung cancer yelded a global survival rate of $77.7 \%$ at three years and $63.64 \%$ at five years. For patients younger than 70 years old the rate is significantly ( $p<0.01)$ better $(82.4 \%$ at three years and $72.3 \%$ at five years). ${ }^{7}$ Other large clinical series have confirmed results similar to those of open resection or even better. ${ }^{2,7-9}$ These good results have been attributed to a more favourable immunological response after VATS, better preservation of cell-mediated immunity, reduced release of stress hormones, and lower levels of C-reactive protein and IL-6. ${ }^{10,8}$

VATS resection should follow the same principles as oncologic surgery, and the desire to offer the patient the advantages of VATS resection should not authorise one to perform lesser resection in case of difficult lobectomy. Formal lobectomy is the standard; however, sublobar resections are acceptable in frail patients. Despite the initial 
studies stressing the increased rate of local recurrences after segmentectomy or wedge resection, many authors now report very good results after sublobar resection. The problem is still open.

\section{INDICATIONS}

Indications are not unanimously defined. We limit VATS lobectomy to peripheral T1N0 and T2N0 lung cancer with no infiltration of the lobar bronchus, no atelectasis, or infiltration of the parietal pleura, even though VATS lobectomy for cancer is technically feasible in many other conditions.

\section{TECHNIQUE}

The patient is intubated with a double lumen Carlens tube for selective ventilation or collapse of the chosen lung, and in lateral decubitus as for postero-lateral thoracotomy. A pillow is placed under the chest, and the table is flexed in order to avoid any limitation on movements of the camera by the iliac crest.

The surgical team is positioned according to Fig. 1. Positions will change depending on the different steps of the operation.

The optics are inserted in the seventh or eighth intercostal space on the mid-axillary line. A second port is inserted in the fourth or fifth space posteriorly and a $3-4 \mathrm{~cm}$ incision is carried out along the inframammary sulcus in the third or fourth space, where the intercostal spaces are wider and no major muscles must be sectioned. This "utility thoracotomy" permits the introduction of non-endoscopic instruments, provides useful access in case of problems, and ensures the extraction of the specimen at the end of the resection. Rib spreaders are not used except for extracting the specimen, in order to prevent nerve damage and reduce postoperative pain.

We always start the procedure with a thorough "surgical" exploration (which we have called videothoracoscopic operative staging, VOS) of the pleural cavity to rule out inoperability and to confirm the 


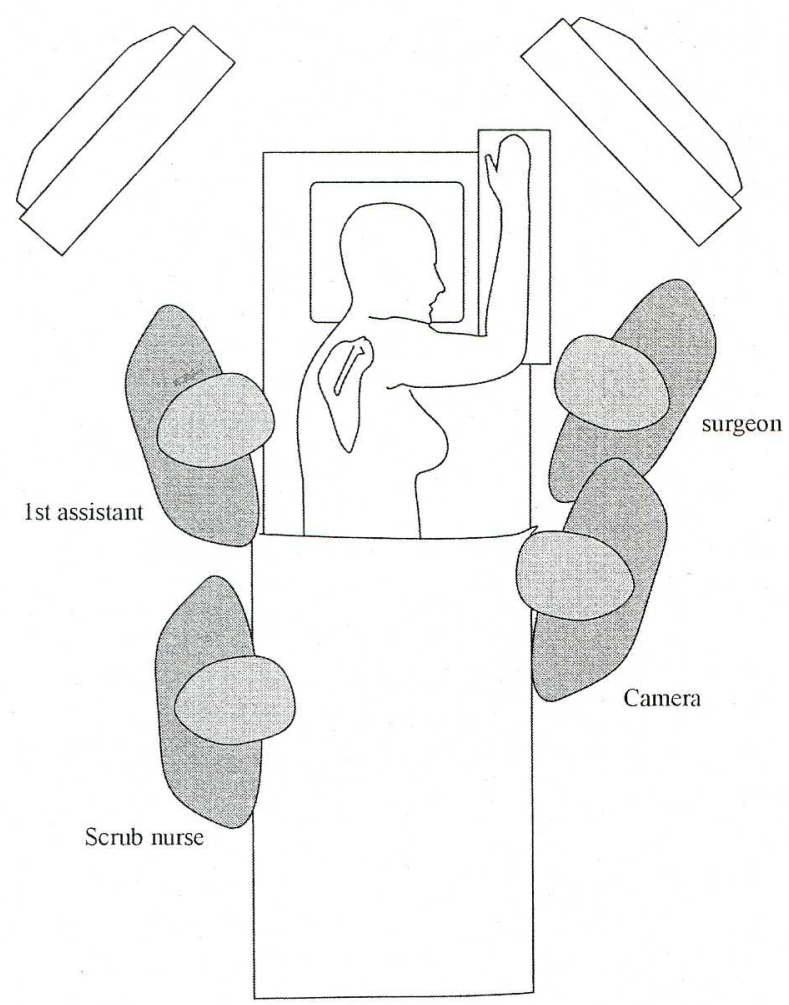

FIGURE 1 Positioning of the patient, the team and the equipment. Two monitors are placed at the head of the patient who is in lateral decubitus. The surgeons usually stands in front of the patient. Positions of the team can change rapidly.

videothoracoscopic feasibility of the lobectomy. This exploration can entail lysis of the adhesions and section of the pulmonary ligament, but also complex manoeuvres such as dividing the azygos vein, or opening the pericardium.

Diffuse pleural adhesions can impair lung collapse, and can call for conversion.

\section{MEDIASTINAL PHASE (FIGS. 2 AND 3)}

Isolation of mediastinal vessels can be achieved with sharp and blunt dissection, through gentle swabbing towards the lung (never in the 

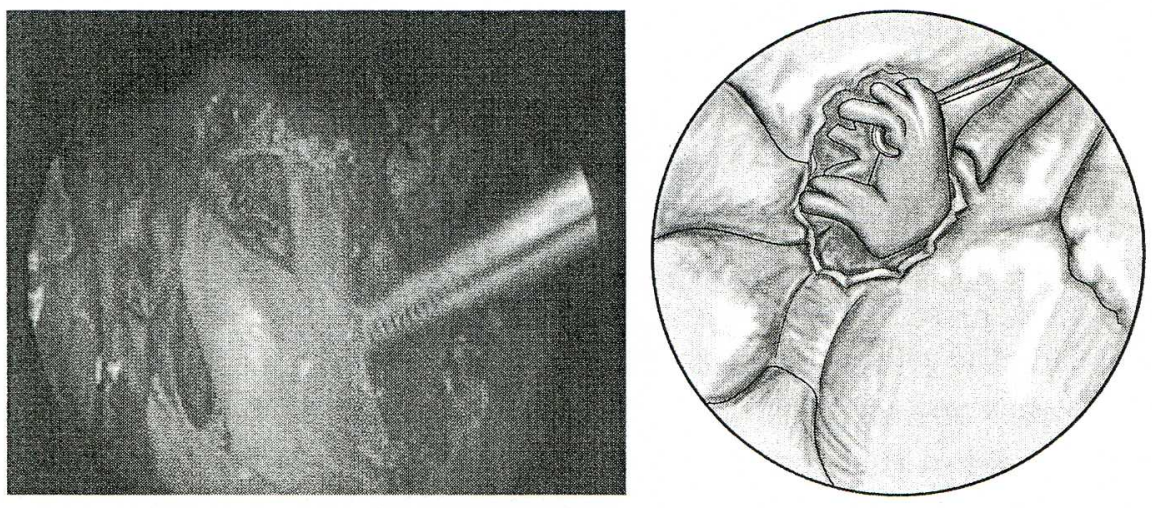

FIGURE 2 Right upper lobectomy: isolation of the right upper pulmonary vein.

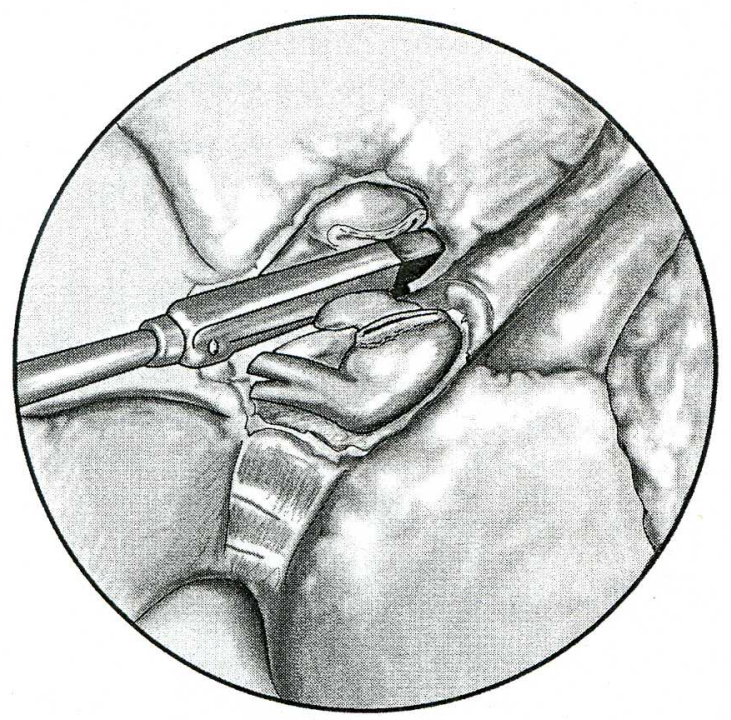

FIGURE 3 Right upper lobectomy: isolation of the anterior trunk.

opposite direction), and must be more extensive than in open surgery, to allow positioning of the endostapler. Once isolated the vessel is encircled with a thread to facilitate the positioning of the stapler. Finding the correct angle of insertion of the stapler can be difficult and changing the site of insertion may be necessary. Any dangerous traction on the instruments must be avoided. As a rule the 
artery is divided before the vein and the bronchus is sectioned last but sometimes it is more convenient to separate the vein before the artery.

\section{FISSURAL PHASE (FIG. 4)}

Isolating the artery within the fissure is a crucial step. The lobar hilum is complex and sometimes lymphnode reaction or partially developec fissure makes the approach more difficult. Once the artery and its branches have been isolated, they can be stapled or clipped according to their size. Smaller vessels, such as veins and arteries for the middle lobe, the lingula, the left upper lobe or the posterior ascending artery can usually be sectioned between clips. An incomplete fissure can bc completed, but sometimes a thick parenchyma must be pressed witl a clamp before stapling it. Sealed fissure or adherent lymphnodes can make the arterial isolation difficult or impossible and can requirt conversion.

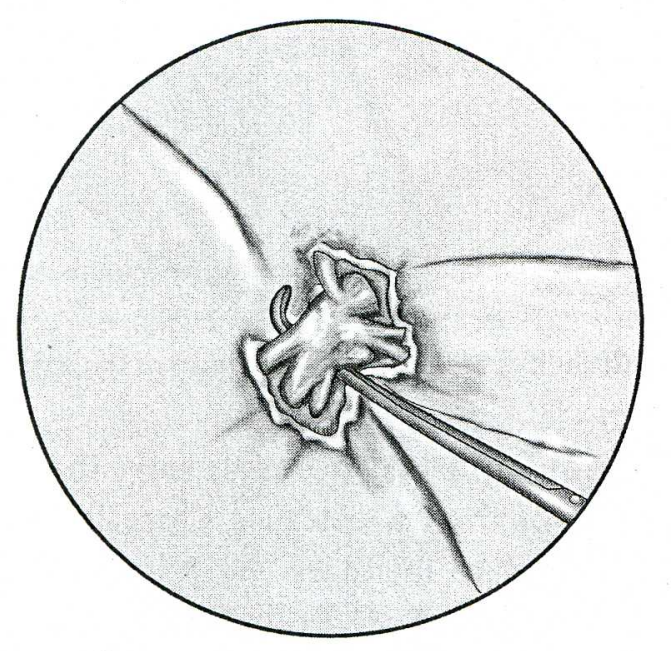

FIGURE 4 Right lower lobectomy: intrafissural isolation and sectioning of the arter to the lower lobe. 


\section{BRONCHIAL PHASE}

The bronchus is usually the last element to be divided. Isolation can be accomplished with a mounted swab, endoscissors and judicious use of electrocoagulation. It must be sufficient to pass the endostapler, but vascularisation of the stump must be preserved. Lobar bronchi are usually secured with $3.5 \mathrm{~mm}$ staples, whereas the main stem bronchus or thickened lobar bronchi require $4.8 \mathrm{~mm}$ staples.

\section{LYMPHADENECTOMY}

VATS lymphadenectomy is technically feasible to the same extent as open surgery and follows the same steps.

All suspect lymphnodes are sent for frozen section examination and, when the response is positive, we convert the intervention to an open procedure, irrespective of whatever phase of the procedure has been reached.

In skilled hands and with accurate selection of patients, VATS lobectomy for cancer is a safe and valid alternative to the conventional open procedure, with similar short- and long-term results. Notwithstanding, larger series are needed to confirm these attractive results.

\section{REFERENCES}

1. Roviaro GC, Varoli F, Vergani C, Maciocco M, Nucca O, Pagano C. (2004) Video-assisted thoracoscopic major pulmonary resections: technical aspects, personal series of 259 patients, and review of the literature. Surg Endosc 18: 1551-1558.

2. Naruke T. (2000) Thoracoscopic lobectomy with mediastinal lymph node dissection or sampling. In: Yim APC, Hazelrigg SR, Izzat MB et al., (eds.), Minimal Access Cardiothoracic Surgery. Philadelphia, PA, WB Saunders, pp. 116-126.

3. Kaseda S, Aoki T, Hangai N. (1998) Video-assisted thoracic surgery (VATS) lobectomy: the Japanese experience. Semin Thorac Cardiovasc Surg 10: 300-304. 
4. Yim APC. (2002) VATS major pulmonary resection revisited - controversies, techniques, and results. Ann Thorac Surg 74: 615-623.

5. McKenna RJ Jr et al. (1998) VATS lobectomy: the Los Angeles experience. Semin Thorac Cardiovasc Surg 10: 321.

6. Roviaro GC, Rebuffat C, Varoli F, et al. (1992) Videoendoscopic pulmonary lobectomy for cancer. Surg Laparosc Endosc 2: 244-247.

7. Roviaro GC, Varoli F, Vergani C, Nucca O, Maciocco M, Grignani F. (2004) Long-term survival after videothoracoscopic lobectomy for stage I lung cancer. Chest 126: 725-732.

8. Walker SW, Codispoti M, Soon SY, et al. (2003) Long-term outcomes following VATS lobectomy for non-small cell bronchogenic carcinoma. Eur J Cardiothorac Surg 23: 397-402.

9. Sugiura H, Morikawa T, Kaji M, et al. (1999) Long-term benefits for the quality of life after video-assisted thoracoscopic lobectomy in patients with lung cancer. Surg Laparosc Endosc 9: 403-410.

10. Sugi K, Kaneda Y, Esato K. (2000) Video-assisted thoracoscopic lobectomy reduces cytokine production more than conventional open lobectomy. Jpn J Thorac Cardiovasc Surg 48: 161-165.

11. Kirby TJ, Mack MJ, Landreneau RJ, et al. (1993) Initial experience with video-assisted thoracoscopic lobectomy. Ann Thorac Surg 56: 1248-1253.

12. Lewis RJ, Caccavale RJ. (1998) VATS lobectomy. Semin Thorac Cardiovasc Surg 10: 332-339. 